\title{
A Study on Conversion of Parts of Speech in English-Chinese Translation
}

\author{
Zhengxi Liu and Ru Yuan* \\ Wuhan University of Science and Technology, Wuhan, Hubei, China \\ 463544134@qq.com, 454141674@qq.com
}

\section{Keywords: English-Chinese translation; Parts of speech; Conversion}

\begin{abstract}
English is distinct from Chinese in terms of means of expression, sentence structure, grammar and culture. The text analyses the common skill from the aspect of necessity of conversion and the application of conversion in E-C translation. At first, it gives a brief introduction to the definition of conversion of parts of speech. Next, it throws light upon the necessity of conversion of parts of speech, including classification of parts of speech as well as causes for conversion of parts of speech. Then, the author gives abundant examples for readers to engrave the skill, comprising conversion between noun, adjective and adverb. The last part concludes the text with concise point that translators should employ the conversion skillfully and flexibly on the basis of fully aware of the diversity between English and Chinese.
\end{abstract}

\section{Introduction}

"By conversion, we mean that in translation a word in one language belonging to a certain part of speech is not necessarily to be turned into one of the same part of speech in another language." ${ }^{[1]}$. The purpose of conversion is to faithfully convey the meaning of the original at the same time accords with Chinese means of expression irrespective of the part of speech of a word in English. Conversion is necessary in E-C translation. Translators should make corresponding change according to the context and means of expression on condition of not altering the meaning of the original word. Important as conversion is, it will lead to unexpected consequences if coped with improperly. Firstly, the content of the version is in accordance with the original but doesn't conform with Chinese means of expression. Secondly, the version seems to correspond Chinese means of expression but the content doesn't fit the original.

In E-C translation, almost all parts of speech can be converted between each other. For instance, nouns can be converted into adverbs and adjectives, verbs can be converted into nouns and adverbs and adjectives can be converted into nouns and adverbs. However, better translation practice lies in better understanding of the rules.

\section{Necessity}

The author unmasks the necessity of conversion with regard to the two languages' differences in vocabulary and sentence structure.

Firstly, plenty of English words can change their parts of speech and meanings by means of adding affix while a great number of Chinese words can't. Professor Yang fengning proclaims that, from the perspective of morphological characteristics of vocabulary, Chinese is vested in isolating language(each word is composed of one morpheme). Compared with Chinese, English is partial to inflectional language, also known for comprehensive language(the change of part of speech in each word shows changes in meaning or grammatical function) ${ }^{[2]}$.

Secondly, English sentences emphasize on logicality with a complee structure while Chinese sentences start with a topic without change in forms of words. Therefore, it is undeniable that sentence structure in E-C translation should be changed, which is often accompanied by conversion of parts of speech.

According to aforementioned points of view, in most cases, it is unfeasible to translate English word for word into Chinese. As professor Huang zhoucheng and professor Liu liyun put it, " Then 
conversion is required for translators to make translation version not only read natural but also get used to the rule of target language and thinking habits of readers." [3]

Classification of Parts of Speech. English is characterized by adequate formal denotation and crystallized division of grammatical function. Conversely, Chinese seems to have no strict formal change, which has blurred grammatical function division. And the relationship between its part of speech and syntactic constituent is intricate rather than corresponding.

Classification of English Parts of Speech. We can judge the parts of speech of some English words according to their suffix. Suffix of noun are er, or, ness, hood and so on; Suffix of adjective are y, al, ese, ful; Suffix of adverb are ly and wards; Suffix of verb are, ize, ify, en. Noun has two other external denotation apart from aforementioned markers, namely, preposition and article. For example, it must be a noun with article the or $a(n)$ in front, or with a preposition ahead, so it is easier to tell a noun. Verb, however, has three suffix markers but the majority of single verb can't tell its part of speech merely from its form. The only way out is to put it in a sentence and tell its part of speech according to its relationship with the subject.

Although markers of English parts of speech outnumber Chinese, affix which can be used as morphological markers is in the decline in the transition from old English to modern English. Furthermore, standard of classifying parts of speech gives priority to grammatical features and sentence structure rather than meaning. Thus, only by putting these words, especially those have more than one part of speech, in a sentence, can we tell their parts of speech.

Classification of Chinese Parts of Speech. How to classify Chinese parts of speech since there are few formal markers? At the very beginning, Semanteme is used as a standard of classification, but it has disadvantages in both theory and practice. Because one word has different parts of speech when it is placed in different phrases or sentences. Later, scholars reach a consensus on that the part of speech of one word can't be distinguished purely from its meaning, function should be taken into consideration.

To sum up, since Chinese syntactic constituent doesn't correspond with parts of speech, it's necessary to classify parts of speech according to both semanteme and function.

Reasons for Conversion of Various Kinds. The biggest reason for conversion lies in differences in sentence construction between English and Chinese. English belongs to Indo-European family while Chinese belongs to Sino-Tibetan family; English has plentiful connective words such as "who", "when", "because" and so on, which help English speakers well organize speeches. Nevertheless, Chinese may convey intact thoughts logically without a single connective word.

These differences result from hypotaxis and parataxis. "Hypotaxis is the relation between a dependent element and its dominant, the element on which it is dependent. Contrasting with this is parataxis, which is the relation between two like elements of equal status, one initiating and the other continuing. In principle, the paratactic relation is logically symmetrical and transitive. The hypotactic relation is logically non-symmetrical and non-transitive." [4]. According to Halliday, English is undoubtedly hypotaxis-prominent while Chinese is parataxis-prominent. English speakers tend to achieve the integrity and compactness of sentences with the aid of connective words. On the contrary, Chinese speakers stress greater importance to inner logic of sentences rather than connectives. Hence, Chinese sentence is implied, concise, and comprehensive.

\section{Examples of Conversion Between Parts of Speech}

Professor Zhang peiji reckons that in the process of E-C translation, some sentences are able to translate word for word while some sentences, due to difference in means of expression between English and Chinese, can't embrace the way as one hole for one radish ${ }^{[5]}$.

Conversion between various parts of speech contains: English nouns can be converted into Chinese verbs, adjectives and adverbs; English adjectives can be converted into Chinese verbs, nouns and adverbs; English adverbs can be converted into Chinese nouns, verbs and adjectives; English verbs can be converted into Chinese nouns and adverbs; English prepositions can be converted into Chinese verbs and conjunctions. 
The following table 1 can give us some examples for better understands for Conversion Between Parts of Speech. When we do some English-Chinese translation exercise, much attention should be paid to the underlined words. Such translation strategies can improve the quality of the versions.

Table 1 Some examples for transferred part of speech

\begin{tabular}{|c|c|c|}
\hline Original Part of Speech & Transferred Part of Speech & Examples \\
\hline \multirow{3}{*}{ English nouns } & \multirow{3}{*}{ Chinese verbs } & $\begin{array}{l}\text { 1. The meeting was a huge } \\
\text { success. }\end{array}$ \\
\hline & & \\
\hline & & $\begin{array}{l}\text { 2. The sight of the sweater } \\
\text { reminds me of my } \\
\text { husband. }\end{array}$ \\
\hline \multirow{2}{*}{ English nouns } & \multirow{2}{*}{ Chinese adjectives } & $\begin{array}{l}\text { 1. The security and } \\
\text { warmth of the ward were } \\
\text { wonderful, }\end{array}$ \\
\hline & & $\begin{array}{l}\text { 2. Independent thinking is } \\
\text { an absolute necessity in } \\
\text { study. }\end{array}$ \\
\hline \multirow{2}{*}{ English nouns } & \multirow{2}{*}{ Chinese adverbs } & $\begin{array}{l}\text { 1. The new mayor earned } \\
\text { some appreciation by the } \\
\text { courtesy of coming to visit } \\
\text { the poor. }\end{array}$ \\
\hline & & $\begin{array}{l}\text { 2. She added with smiling } \\
\text { cynicism. }\end{array}$ \\
\hline \multirow{2}{*}{ English adjectives } & \multirow{2}{*}{ Chinese verbs } & $\begin{array}{c}\text { 1. We were impatient with } \\
\text { those who took a cautious } \\
\text { approach. }\end{array}$ \\
\hline & & $\begin{array}{l}\text { 2. I think he is very fond } \\
\text { of me. }\end{array}$ \\
\hline
\end{tabular}




\begin{tabular}{|c|c|c|}
\hline \multirow{2}{*}{ English adjectives } & \multirow{2}{*}{ Chinese nouns } & $\begin{array}{l}\text { 1. They did their best to } \\
\text { help the sick and the } \\
\text { wounded. }\end{array}$ \\
\hline & & $\begin{array}{l}\text { 2. After careful treatment, } \\
\text { the deaf have recovered } \\
\text { their hearing. }\end{array}$ \\
\hline \multirow{2}{*}{ English adjective } & \multirow{2}{*}{ Chinese adverbs } & $\begin{array}{l}\text { 1. In preparation, I was } \\
\text { paying close attention to } \\
\text { my own interactions. }\end{array}$ \\
\hline & & $\begin{array}{l}\text { 2. The police made a } \\
\underline{\text { careful study of the }} \\
\text { evidence. }\end{array}$ \\
\hline \multirow{2}{*}{ English adverbs } & \multirow{2}{*}{ Chinese nouns } & $\begin{array}{l}\text { 1. He is physically weak } \\
\text { but mentally sound. }\end{array}$ \\
\hline & & $\begin{array}{l}\text { 2. First, I realized how I } \\
\text { distorted my view of other } \\
\text { people when I reacted } \\
\text { defensively. }\end{array}$ \\
\hline \multirow{2}{*}{ English adverbs } & \multirow{2}{*}{ Chinese verbs } & $\begin{array}{l}\text { 1. As he went out, he } \\
\text { forgot to have his shoes } \\
\text { on. }\end{array}$ \\
\hline & & $\begin{array}{l}\text { 2. The huge polar bear } \\
\text { turned and ambled away. }\end{array}$ \\
\hline \multirow{2}{*}{ English adverbs } & \multirow{2}{*}{ Chinese adjectives } & 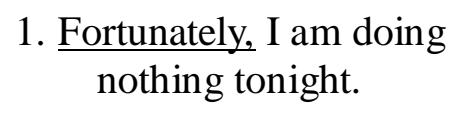 \\
\hline & & $\begin{array}{l}\text { I think the boss was } \\
\text { favorably impressed by } \\
\text { your presentation. }\end{array}$ \\
\hline
\end{tabular}




\begin{tabular}{|c|c|c|}
\hline English verbs & Chinese adverbs & $\begin{array}{c}\text { She kept us all waiting a } \\
\text { little and at last she sailed } \\
\text { in. }\end{array}$ \\
\hline
\end{tabular}

\section{Conclusion}

English differs greatly from Chinese in many aspects, including vocabulary, sentence structure and grammar etc. ${ }^{[6]}$ Nouns, prepositions, adjectives and adverbs in English have strong expressiveness and they are more extensively used than in Chinese, while verbs and short sentences in Chinese are used widely more than in English. In E-C translation, conversion of parts of speech is inseparable if you want to convey the original authentically at same time display Chinese language's characteristics. Otherwise, too much emphasis on equivalence in form would spoil the version. The requirement of translation is to faithfully express the thoughts and style of the original, and conversion exactly serves as a catalyst of breaking through incoherence. Against a backdrop, it is advisable for a translator to employ conversion of parts of speech on the basis of proficiency in diversity between English and Chinese. Although conversion is very flexible and has no fixed form or limitations, we still can sum up some rules. On the basis of rules of conversion along with the author's translation practice, the thesis analyses conversion of various parts of speech in detail and holds affirmative attitudes to conversion.

\section{References}

[1] D.Y. Lu. Translation: It's principles and Technique. 1958. No.1, p46-47.(In Chinese)

[2] F.L.Yang. Contrastive Studies \& Translation of English and Chinese,(2006)No.1, p125-126.(In Chinese)

[3] C.Z.Huang and L.Y. Liu. English \& Chinese Translation Technique, (2008)No.1, p34-35.(In Chinese)

[4] Halliday, M.A.K. Exploration in functions of language. (London: Edward Arnold, 1973)

[5] P.J.Zhang. A Course English-Chinese Translation(2009)No.1, p79-80.(In Chinese)

[6] Newmark, Peter. About Translation(2006)No.1, p231-232.(In Chinese) 